\title{
Letters
}

Website: www.bmj.com

Email: letters@bmj.com

\section{Developing world needs access to low cost pharmaceutical information from reliable sources}

EDITOR-Hafeez and Mirza have assessed how seriously (or not) pharmaceutical companies take their responsibility to provide information on request to prescribers in Pakistan. ${ }^{1}$ Two of their conclusions are that "providing information on drugs is not a priority for companies in Pakistan" and that "the decision to respond to a request for more information therefore seems to depend on how favourable it might be to the interests of the company." These conclusions are particularly worrying because the biased information from drug companies is often the only type of information that prescribers have access to.

The findings are in one respect an indictment of the pharmaceutical industry's approach in the developing world. But in another respect, the fact that most prescribers in the developing world do not have adequate access to reliable generic information is an indictment of the international health community. We cannot and should not expect the pharmaceutical industry to provide consistently unbiased information. What is needed is universal access to free or low cost information from a reliable source.

\section{Advice to authors}

We prefer to receive all responses electronically, sent either directly to our website or to the editorial office as email or on a disk. Processing your letter will be delayed unless it arrives in an electronic form.

We are now posting all direct submissions to our website within 24 hours of receipt and our intention is to post all other electronic submissions there as well. All responses will be eligible for publication in the paper journal.

Responses should be under 400 words and relate to articles published in the preceding month. They should include $\leqslant 5$ references, in the Vancouver style, including one to the BMJ article to which they relate. We welcome illustrations.

Please supply each author's current appointment and full address, and a phone or fax number or email address for the corresponding author. We ask authors to declare any competing interest. Please send a stamped addressed envelope if you would like to know whether your letter has been accepted or rejected.

Letters will be edited and may be shortened.

www.bmj.com

letters@bmj.com
As a basic source of reliable prescribing information, the British National Formulary is arguably the single most useful formulary for prescribers worldwide and is one of the BMJ Publishing Group's best sellers internationally. We applaud the recent decision to make the $e B N F$ available on line. ${ }^{2}$ If this facility is free it will be a benefit to some prescribers in developing countries, although the effort required to get information online will always be a barrier, even to those few who do have access.

Low cost, printed formularies with a quality and objectivity parallel to those of the British National Formulary should be made affordable to all prescribers. Their value and use should be vigorously promoted, not just by the BMJ Publishing Group but by the international health community at large.

Neil Pakenham-Walsh programme manager INASP-Health International Network for the Availability of Scientific Publications, Oxford OX1 1HU

101374.3615@compuserve.com

Michael Eddleston senior house officer

Royal Sussex County Hospital, Brighton BN2 5BE

Manjit Kaur pharmaceutical adviser

ECHO International Health Services, Coulsdon, Surrey CR5 2HR

1 Hafeez A, Mirza Z. Responses from pharmaceutical companies to doctors' requests for more drug information in Pakistan: postal survey. BMj 1999;319:547. (28 August.) Delamothe T, Smith R. The joy of being electronic. $B M J$
1999;319:465-6. (21 August.)

\section{Research questions for systematic reviews must be unambiguous from protocol stage}

EDITOR-The systematic review of Walton et al aimed to "identify all comparative studies in which computers were used to help determine the most appropriate drug dose," including studies in which participants are "patients receiving drug therapy based on advice from a computer."' According to this protocol, the authors clearly should have included studies in which advice is given direct to patients, nurses, or intermediates, such as in software applications for diabetes management. ${ }^{3}$ Such studies, however, were not mentioned, even though insulin treatment in diabetes (having clear physiological indicators?) would have been a particularly good model for evaluating the usefulness of computerised drug advice, and contamination effects in the study design cannot occur.

I would have expected a discussion of the apparent omission of such studies in which advice was given to other healthcare professionals or the patient. Instead, readers are confused by the ill defined scope of this review and are left with the impression that the authors made their minds up as they went along.

This unsystematic approach is also reflected by the inadequate retrieval strategy. The search word prescr* is applied for the broad concept of drugs, including drugs given by computer controlled infusion pumps, which the authors explicitly wanted to cover. But at least 261200 Medline articles deal with pharmaceutical preparations but do not use the word stem prescr*. For example, studies indexed with the MeSH term "infusion pumps" in combination with a phrase indicating computer control (such as Murchie and Kenny's study ${ }^{4}$ ) or studies dealing with non-prescription drugs would not be retrieved. Equally insensitive is the use of the search term comput*, as at least 9967 Medline articles use the word "software" or "expert system" without mentioning comput*. This may lead to selection bias, as studies dealing with more sophisticated "expert systems" for drug advice may have been missed. Further, the authors claimed to have searched for other research designs such as interrupted time series, but, confusingly, this is not reflected in the search term "randomised controlled trial" or "random allocation" or "double blind method."

These problems illustrate the importance of making the research question unambiguous at the protocol stage. The terminology used must be defined (in this case, What is computerised advice? Advice given to whom? What kind of drugs?), and a search strategy must be carefully planned in collaboration with an experienced information broker.

Gunther Eysenbach researcher

University of Heidelberg, Department of Clinical Social Medicine, Unit for Cybermedicine, 69115 Heidelberg, Germany

ey@yi.com

\footnotetext{
1 Walton R, Dovey S, Harvey E, Freemantle N. Computer support for determining drug dose: systematic review and meta-analysis. BMJ 1999;318:984-90. (10 April.)

2 Walton RT, Harvey EL, Dovey S, Freemantle N. Computerised advice on drug dosage to improve prescribing practice (protocol for a Cochrane review). In: Cochrane Library. Issue 1. Oxford: Update Software, 1999.
} 
3 Peterson CM, Jovanovic L, Chanoch LH. Randomized trial of computer-assisted insulin delivery in patients with type I diabetes beginning pump therapy. Am J Med 1986;81:6972. (A further 6 references are cited in www.bmj.com/cgi/ eletters/318/7189/984\#EL1.)

4 Murchie CJ, Kenny GN. Comparison among manual, computer-assisted, and closed-loop control of blood pressure after cardiac surgery. I Cardiothorac Anesth 1989;3: $16-9$.

\section{Chaperones for genital examination}

\section{Chaperones should always be present}

EDITOR-Bignell states in his editorial that "it is difficult not to proceed with a clinically indicated examination if the patient declines a chaperone, providing the physician feels comfortable in this situation." I would say that this reads in much the same way as "it is difficult not to proceed with sexual intercourse if the man declines to use a condom, providing the woman feels comfortable in this situation." The analogy is valid, I believe, as sexually transmitted disease (including HIV infection and unwanted pregnancy) carries much the same mortality as allegations of sexual assault, to patient and doctor respectively, however comfortable they may feel at the time.

If clinical governance and risk management are to mean anything it surely must be that entirely preventable disasters such as allegations of sexual assault, exclusively associated with the performance of intimate but unchaperoned examinations, are consigned to history. This should be done by a corporate policy that requires all intimate examinations to be carried out in the presence of a chaperone of the appropriate sex, unless exceptional circumstances prevail. Individual patients might not like this, but the safety of healthcare workers should not be subservient to patients' whims.

Michael Croft general medical practitioner West Herts Community NHS Trust PMS Pilot, Gateways Surgery, Shenley, Hertfordshire WD7 9LL

106750.317@compuserve.com 1 Bignell CJ. Chaperones for genital examination. BMJ
1999;319:137-8. (17 July.)

\section{We should offer a chaperone but not inflict one}

EDITOR-"For medicolegal reasons a third party should always be present during genital examination" is an unfortunate comment in an otherwise useful and balanced editorial. ${ }^{1}$ Such bald statements have a tendency to be quoted as established good practice by the uninformed.

Whether a consultation takes place at home, in a general practice surgery, or at an outpatient clinic, the fundamental right of all patients (of either sex or any sexuality) is to maintain their autonomy and to make informed decisions for themselves. This must extend to the presence or absence of a chaperone, and we should respect their wishes.

The offer of a chaperone is generally appropriate, although-particularly in general practice-it can offend some patients, who interpret it as a lack of trust in them by their doctor. When made, the offer of a chaperone must be exactly that-a genuine offer and not an unwanted imposition of a spectator for an already potentially sensitive consultation. Patients have a right to a professional examination without an uninvolved third party being present.

Let us not submerge our professionalism in a rising tide of neurotic guidelines Patient choice and rights must not be subservient to medicolegal paranoia. We should offer chaperones but not make them compulsory.

James Morrow general practitioner

The Doctors' House, Marlow, Buckinghamshire

SL7 1DN

james@marlowdocs.demon.co.uk 1 Bignell CJ. Chaperones for genital examination. BMJ
1999;319:137-8. (17 July.)

Presence of chaperone may interfere with doctor-patient relationship

EDITOR-After publication of a document on intimate examinations by the Royal College of Obstetricians and Gynaecologists, the Faculty of Family Planning and Reproductive Health Care considered important issues specific to its own discipline and subsequently issued guidance. ${ }^{2}$ Some of these issues have not been completely addressed by Torrence et al's study on the use of chaperones in genitourinary medicine ${ }^{3}$ or the accompanying editorial. ${ }^{4}$

In gynaecology and genitourinary medicine a chaperone is usually used when the clinician and client are of different sexes Most staff and clients in family planning clinics, however, are women, and we find that most clients do not expect or wish to have a chaperone. Clinics may have only two or three clinical staff present at any time, all of whom are usually seeing clients; in addition, many sessions are held in the evening, when other staff, who could have acted as chaperones, have left. Nurses are increasingly developing their own roles, working alone in nurse led clinics, where there is no one to act as a chaperone.

This reinforces Torrence et al's comments that many clinics would not normally have sufficient appropriate staff to be able to offer a chaperone for every intimate examination without considerably lengthening waiting times for clients. This, or the option of returning when a chaperone is present, may negate any postulated benefit that this practice may offer.

Family planning clinics often offer other specialist services, including psychosexual counselling. A fundamental principle here is the observation of the doctor-patient relationship, and the genital examination is a part of the assessment. The presence of a third person, a chaperone, may unbalance the interview, and patients may be unable to articulate their innermost fears or fantasies in the presence of the third person.

The Faculty of Family Planning and Reproductive Health Care therefore produced the following pragmatic guidance for staff:
- All clients should be advised that they may ask for a chaperone to be present

- The healthcare professional must believe that the intimate examination is necessary and will assist with the patient's care

- If a trainee is to undertake the examination s/he will be supervised

- The client must be treated with dignity and respect

- An interpreter or advocate will be present if requested

- Verbal consent must have been given after appropriate explanation.

Sarah Randall consultant community gynaecologist Ella Gordon Unit, St Mary's Hospital, Portsmouth PO3 6AF

Anne Webb consultant in family planning and reproductive health care awebb@westkirbyl.freeserve.co.uk

Meera Kishen consultant in family planning and reproductive health care

North Mersey Community NHS Trust, Liverpoo L2 5SF

1 Royal College of Obstetricians and Gynaecologist. Intimate examinations: a report of a working party. London: RCOG, 1997.

2 Randall S. Intimate examination. Br J Fam Plann 1998;24: $83-4$

3 Torrence CJ, Das R, Allison MC. Use of chaperones in clinics in genitourinary medicine: survey of consultants. BMJ 1999;319:159-60. (17 July.)

4 Bignell CJ. Chaperones for genital examination. BMI 1999;319:137-8. (17 July.)

\section{Patients' physical disability may influence doctors' perceptions of suitability for risk assessment of $\mathrm{CHD}$}

EDITOR-Gardener et al have raised the issue of barriers to referral in patients with angina, pointing to cultural gaps and perceptions leading to diagnostic confusion and inequality of referral for coronary revascularisation. ${ }^{1}$ Addressing this issue is essential for meeting the Health of the Nation target to reduce cardiovascular deaths.

Patients' perceptions are only one of the factors that lead to referral barriers. Doctors' perceptions of patients' suitability can also have profound implications for referral patterns for risk assessment of coronary heart disease and subsequent revascularisation. For example, the presence of physical disability may result in doctors believing that risk assessment by exercise testing would be inappropriate or impossible. Thus a disabled patient may fall at the first referral hurdle.

Rheumatoid arthritis is associated with increased cardiovascular mortality, ${ }^{2}$ the most likely cause of which is cardiovascular disease. We have systematically reviewed the records of 4000 consecutive patients who underwent coronary angiography over five years. On the basis of a prevalence of rheumatoid arthritis of 1-2\%, we expected to find 40-80 patients who also had rheumatoid arthritis but in fact found only three. It seems that in everyday practice cardiovascular disease is not considered a condition worthy of investigation in patients with rheumatoid arthritis. 
We have assessed the presence of cardiovascular disease in 65 random patients attending the rheumatoid arthritis outpatients clinic (mean age 59 (range 40-70)). Forty six of these patients required a cane to walk long distances, while a further 13 used a wheelchair. None of them felt able to exercise fully, an essential requirement for adequate exercise testing. ${ }^{3}$ Despite this they were all successfully assessed for the presence of cardiovascular disease by adenosine-stressed myocardial perfusion imaging. Prevalent cardiovascular disease was $50 \%$, half of which was prognostically high risk. The patients at highest risk were men with early onset and more aggressive rheumatoid arthritis.

Rheumatoid arthritis is only one example of conditions characterised by both increased risk of cardiovascular disease and physical disability. Other examples include diabetic amputation, systemic lupus erythematosus, and peripheral vascular disease. Myocardial perfusion imaging may be an ideal noninvasive diagnostic and prognostic test for risk assessment of cardiovascular disease in disabled patients: it is highly sensitive and specific for the detection of cardiovascular disease and gives prognostic information superior to that given by exercise testing. ${ }^{5}$

Physical disablement and doctors' perception of inability to perform exercise testing should not be a barrier to referral for diagnosis and risk assessment of cardiovascular disease.

Matthew Banks clinical research fellow, department of cardiology

George Kitas senior lecturer, department of

rheumatology

Dudley Group of Hospitals NHS Trust, Dudley,

West Midlands DY8 5QX

Mat@dirtyb.freeserve.co.uk

1 Gardener K, Chapple A. Barriers to referral in patient with angina: qualitative study [with commentary by Green]. BMJ 1999;319:418-21. (14 August)

2 Wallberg-Jonsson S, Ohman M-L, Dahlqvist SR. Cardiovascular morbidity and mortality in patients with seropositive rheumatoid arthritis in Sweden. I Rheumatol 1997:24:445-51.

3 Banks MJ, Flint EJ, Kitas GD. The role of pharmacologically stressed 201 thallium myocardial perfusion imaging cally stressed 201thallium myocardial perfusion imaging in rheumato

4 Banks MJ, Flint EJ, Kitas GD. Expression and prevalence of Banks MJ, Flint EJ, Kitas GD. Expression and prevalence of
ischaemic heart disease in rheumatoid arthritis [abstract] ischaemic heart disease in rhe

5 Arthritis Rheum 1998;41:S209.

5 Pennell DJ, Mavrogeni SI, Forbat SM, Karwatowski SP Underwood SR. Adenosine combined with dynamic exercise for myocardial perfusion imaging. J Am Coll Cardio 1995;25:1300-9.

\section{Alcohol consumption and mortality}

\section{Underestimates of consumption are possible}

EDITOR-Hart et al say that the mortality curve in relation to alcohol consumption may not be $\mathrm{U}$ shaped or $\mathrm{J}$ shaped once socioeconomic and confounding factors are taken into account. ${ }^{1}$ We should like to raise concerns about the estimates of weekly alcohol consumption used, in particular by taking one bottle of wine to be equivalent to six units of alcohol. This value is only true
Alcohol content of a selection of supermarket wines

\begin{tabular}{lccc} 
& $\begin{array}{c}\text { Alcohol } \% \\
\text { by volume }\end{array}$ & \multicolumn{2}{c}{ Units of alcohol } \\
\cline { 3 - 4 } & $\mathbf{1 2 5} \mathbf{~ m l}$ glass & $\mathbf{7 5 0} \mathbf{~ m l ~ b o t t l e ~}$ \\
\hline White wine $^{*}$ & $12-13$ & $1.5-1.6$ & $9-9.6$ \\
\hline Red wine & $12-13.5$ & $1.5-1.6$ & $9-9.6$ \\
\hline German & $8.5-10$ & $1.2-1.3$ & $7.2-7.8$
\end{tabular}

wine

*Not German

for a $750 \mathrm{ml}$ bottle of wine that is $8 \%$ alcohol by volume. Apart from some German wines, most wines are between $11 \%$ and $13.5 \%$ alcohol by volume. Many supermarket wines now state how many units of alcohol are contained in each $125 \mathrm{ml}$ glass.

Our brief survey in a large supermarket to assess their alcohol contents of a random selection of wines (table) shows that the actual number of units consumed in wine could be underestimated by as much as $37.5 \%$ per bottle for some types of wine, counting only 6 units of the possible 9.6 units consumed. This would have the effect of placing individuals in lower intake groups than they perhaps ought to be, and attributing to these groups health effects that are actually related to a higher intake. The same concerns could also be true for estimated intake from spirits and beer. If home measures have been taken then this could underestimate the actual consumption because home measures tend to be larger than a single standard pub measure. Many beers contain more than two units of alcohol per pint, which could result in a large underestimate of intake if much beer was consumed. This calls into doubt the reliability of the alcohol consumption figures and could be why the U shaped or J shaped mortality curve was not observed. This concern also brings into question the validity of the other conclusions made in the article.

Martin Ashton-Key specialist registrar in public health

Portsmouth and South East Hampshire Health Authority, Portsmouth PO3 6DP

martin.ashton-key@portsha.swest.nhs.uk

Margaret Ashton-Key consultant histopathologist Royal Sussex County Hospital, Brighton BN2 5BE margaret.ashton-key@brighton-healthcare.com

1 Hart CL, Davey Smith G, Hole DJ, Hawthorne VM. Alcohol consumption and mortality from all causes, coronary heart disease, and stroke: results from a prospective cohort study of Scottish men with 21 years of follow up. BMJ 1999;318:1725-9. (26 June.)

\section{Type of drink has been shown to matter}

EDITOR-The study by Hart et al apparently contradicts the vast number of prospective cohort studies which have shown that one or two alcoholic drinks per day is the optimal intake with regard to risk of coronary heart disease. ${ }^{12}$ In their study, however, drinkers of one or two drinks per day also had a 20-25\% reduction in mortality from coronary heart disease compared with non-drinkers. Adjustment for confounding factors decreased the risk from 0.87 to 0.79 , indicating that alcohol may have a causal role in decreasing risk of death from coronary heart disease. A likely reason for the statisti- cal insignificance of this result is that the study is quite small.

Misclassification may explain the inconsistency in mortality from coronary heart disease between the categories in the lower range of intake. The finding that the risk of alcohol related causes of death increases at an incomprehensively low level (1-7 drinks per week) suggests that a certain underreporting took place. The extremely long follow up time may have added to the poor prediction of both coronary heart disease and alcohol related causes of death among people who changed their drinking habits with age. ${ }^{3}$ Further, this paper does not deal with type of alcohol. Several ecological studies, as well as prospective cohort studies, have found that wine drinkers are better protected against coronary heart disease than are drinkers of beer or spirits. ${ }^{45}$ What do Scottish men drink?

Morten Grønbæk senior research fellow

Danish Epidemiology Science Centre at the

Institute of Preventive Medicine, Copenhagen

University Hospital, Kommunehospitalet, DK-1399

Copenhagen K, Denmark

mg@ipm.hosp.dk

1 Hart CL, Smith GD, Hole DJ, Hawthorne VM. Alcohol consumption and mortality from all causes, coronary heart disease, and stroke: results from a prospective cohort study of Scottish men with 21 years of follow up. BMJ 1999;318:1725-9. (26 June.)

2 Maclure M. Demonstration of deductive meta-analysis: ethanol intake and risk of myocardial infarction. Epidemiol Rev 1993;15:328-51.

3 Shaper AG, Wannamethee SG. The J-shaped curve and changes in drinking habit. In: Chadwick DJ, Goode JA, eds. Alcohol and cardiovascular diseases. Chichester: Wiley, Alcohol and cardiovascular diseases. Chichester: Wiley, 4 Klatsky AL, Armstrong MA. Alcoholic beverage choice Klatsky AL, Armstrong MA. Alcoholic beverage choice and risk of coronary artery disease mortality:

5 Wans fare best? Am J Ca A Type of a Wannaper AG. Type of alcoholic drink and risk of major CHD events and all cause mortality. $A m J$ Public Health 1999;89:685-90.

\section{Authors' reply}

EDITOR-The Ashton-Keys are concerned about the alcohol content of wine and possible underestimation of drinking habits because of the way this was carried out in our study. This is not a major issue in this cohort since only $5.8 \%$ of men were wine drinkers and the wine drunk in the early 1970 s was likely to be of lower alcohol content than today. A nomogram for calculating alcohol content of different beverages in 1970 gave the median value for wine as 10\% by volume. ${ }^{1}$ Recalculating the relative rates of mortality after classifying the wine consumption as nine units per bottle rather than six did not alter the results. With regard to beer, our study was established before the widespread introduction of high alcohol beers, in particular lagers. Though we agree with the comment on home measures being larger than standard pub measures, this will be true for all self reported studies on alcohol.

Grønbæek comments on our study's finding of a statistically non-significant reduction in mortality from coronary heart disease for "moderate" drinkers. However, this effect was not seen in the lower category of 1-7 units per week, making it difficult to draw any firm conclusions. The relative rates of mortality for alcohol related causes were 
Relative rates of lung cancer mortality over 21 years by units of alcohol consumed a week

\begin{tabular}{|c|c|c|c|c|c|c|c|}
\hline & \multicolumn{6}{|c|}{ Units of alcohol per week } & \multirow{2}{*}{$\begin{array}{c}P \\
\text { value } \\
\text { for } \\
\text { trend }\end{array}$} \\
\hline & 0 & $1-7$ & 8-14 & $15-21$ & $22-34$ & $\geqslant 35$ & \\
\hline No of deaths & 49 & 31 & 41 & 18 & 32 & 20 & \\
\hline Adjusted for age & 1 & $\begin{array}{c}1.12 \\
(0.71 \text { to } 1.76) \\
\end{array}$ & $\begin{array}{c}1.58 \\
\text { (1.04 to } 2.39) \\
\end{array}$ & $\begin{array}{c}1.22 \\
(0.71 \text { to } 2.09) \\
\end{array}$ & $\begin{array}{c}2.25 \\
\text { (1.44 to } 3.52) \\
\end{array}$ & $\begin{array}{c}1.86 \\
\text { (1.10 to } 3.13) \\
\end{array}$ & 0.06 \\
\hline $\begin{array}{l}\text { Adjusted for age and social } \\
\text { factors }^{*}\end{array}$ & 1 & $\begin{array}{c}1.22 \\
(0.78 \text { to } 1.92)\end{array}$ & $\begin{array}{c}1.53 \\
\text { (1.01 to } 2.33)\end{array}$ & $\begin{array}{c}1.09 \\
\text { (0.63 to } 1.88)\end{array}$ & $\begin{array}{c}1.94 \\
(1.23 \text { to } 3.05)\end{array}$ & $\begin{array}{c}1.52 \\
(0.89 \text { to } 2.59)\end{array}$ & 0.38 \\
\hline $\begin{array}{l}\text { Adjusted for age, social } \\
\text { factors, }{ }^{*} \text { and smoking }\end{array}$ & 1 & $\begin{array}{c}1.11 \\
(0.71 \text { to } 1.75)\end{array}$ & $\begin{array}{c}1.32 \\
(0.87 \text { to } 2.00)\end{array}$ & $\begin{array}{c}0.85 \\
(0.49 \text { to } 1.47)\end{array}$ & $\begin{array}{c}1.47 \\
\text { (0.93 to } 2.32)\end{array}$ & $\begin{array}{c}1.12 \\
(0.66 \text { to } 1.92)\end{array}$ & 0.92 \\
\hline
\end{tabular}

${ }^{*}$ Social class, father's social class, education, car use, siblings, and deprivation category.

not statistically significant at levels below 15 units per week, so again no firm conclusions can be drawn from these findings. Underreporting may indeed have taken place, but our intake data were similar to other UK studies of the time. Additionally there were high correlations between alcohol reported at the initial screening and at the second screening, four to seven years later, attended by about half of the cohort. This suggests that the alcohol reports are reliable, as do the graded associations between reported alcohol consumption and both blood pressure and triglyceride concentrations.

Beer, spirits, and wine consumption were analysed separately and gave similar results to the analysis of total units of alcohol, but with less power. Of the total units of alcohol reported, $69 \%$ were beer, $28 \%$ spirits and $4 \%$ wine.

Other commentators on our paper considered that residual confounding by smoking could explain our findings with respect to stroke $^{2}$-that is, the men who drank more smoked more, and our measures of smoking were imperfect so we could not take this into account. If this were the case then it would be expected that alcohol would show an independent association with lung cancer mortality. However, as the table shows, this is not the case; while alcohol consumption shows a crude relation to lung cancer mortality, adjustment for smoking and social factors essentially abolishes this, unlike in the case of stroke (see table 2 in the original paper). ${ }^{4}$ Clearly, as lung cancer is considerably more strongly related to smoking than is stroke, residual confounding by smoking would be more clear for lung cancer than stroke as a cause of death.

Carole L Hart research fellow

Department of Public Health, University of Glasgow, Glasgow G12 8RZ

George Davey Smith professor of clinical epidemiology

Department of Social Medicine, University of Bristol, Bristol BS8 2PR

David J Hole principal epidemiologist West of Scotland Cancer Surveillance Unit, University of Glasgow

Victor M Hawthorne professor of epidemiology University of Michigan, School of Public Health, Ann Arbor, MI 48109, USA

1 Mellor CS. Nomogram for calculating mass of alcohol in different beverages. $B M J$ 1970;ii:730.

2 Jacobs A. Was enough attention paid to smoking? Rapid response to www.bmj.com/cgi/content/abstract/318/ response to www.bmj.com/ci
$7200 / 1725$ (accessed 27/8/99).
3 Harkin E. Problem with long term cohort studies relying mainly on baseline data. Rapid response to www.bmj.com/ mainly on baseline data. Rapid response to www.bmj.com/ $\mathrm{cgi} /$ content/abstract/318/7200/1725 (accessed 27/8/99)
4 Hart CL, Davey Smith G, Hole DJ, Hawthorne VM. 4 Hart CL, Davey Smith G, Hole DJ, Hawthorne VM. coronary heart disease and stroke: results from a prospeccoronary heart disease and stroke: results from a prospec-
tive cohort study of Scottish men with 21 years of follow up. BMJ 1999;318:1725-9. (26 June.)

\section{Smoking by young people}

Philip Morris USA also wants to reduce incidence of smoking by young people

EDIToR-Novelli, president of the American activist group Campaign for Tobacco-Free Kids, unfairly characterised the efforts of Philip Morris USA to help prevent smoking by young people. ${ }^{1}$ I would like to set the record straight

We at Philip Morris USA share a common goal with members of the public health community: reducing the incidence of smoking by young people. One indication of my company's commitment to this effort is the creation of our youth smoking prevention department, whose sole goal is to help reduce underage use of tobacco. Our approach is integrated and comprehensive, combining communication and support for school based prevention programmes and community based programmes promoting positive youth development.

We share the view of many experts that an integrated approach is the most effective way to reduce smoking by young people. By itself, of course, advertising is unlikely to reduce underage tobacco use. We do, however, believe that it can play an important part in communicating nonsmoking messages to minors, which is why we produced and placed the advertisements that Novelli condemns.

We stand by these advertisements as being worthwhile in helping to prevent underage smoking. In our extensive research, more than nine out of 10 children said that our advertisements clearly communicated the "don't smoke" message, and nearly three out of four parents said they thought that our advertisements would help convince their children not to smoke. Novelli cites a different study but neglects to mention that its authors say it "cannot be was it meant to be."'

We at Philip Morris USA will continue running these advertisements and making considered statistically reliable or valid-nor other efforts to meet our responsibilities. We recognise that to reduce smoking by young people will require hard work and dedication not just from the tobacco industry but from a variety of people and organisations, including state governments, retailers, law enforcement authorities, community leaders, health organisations, teachers, and families.

We accept the fact that many people question our commitment to do the right thing. Our hope is that in the long term reasonable people will judge us by our actions. Playing politics will not get us any closer to the goal we all share. Only hard work, based on an understanding of the complexity of what must be done, will make a difference.

Carolyn Levy senior vice president, Youth Smoking Prevention

Philip Morris USA, New York, NY 10017-5592, USA

Carolyn.J.Levy@pmusa.com

1 Novelli WD. "Don't smoke," buy Marlboro. BMJ 1999; 318:1296. (8 May.)

2 Teenage Research Unlimited (USA). Counter-tobacco advertising exploratory: summary report, 1999:4.

\section{Author's reply}

Editor-Despite Levy's claim to the contrary, the public health community has no goals in common with Philip Morris USA. Virtually the entire community worldwide distrusts any initiative by Philip Morris concerning tobacco use by young people. Why is this so?

- Because Philip Morris's global marketing practices continue to influence children, in terms of both beginning to smoke and brand selection. And when Philip Morris and other multinational tobacco companies enter a new national market the country's smoking rates typically increase substantially, especially among underage smokers and women

- Because we believe that Philip Morris's antismoking attempts aimed at young people and its philanthropic giving are strategically designed to purchase legitimacy and to maintain the status quo for as long as possible

- Because any partnerships with Philip Morris send the wrong messages to children about ethics, money, and integrity.

Since the public health community does not trust Philip Morris or want the company to be involved in antismoking interventions aimed at young people, what does it want from Philip Morris? There are many ways in which this company could contribute to meaningful change and reduce the toll of tobacco in much of the world. Two immediate steps stand out:

- Eliminate all marketing that impacts on children by abiding by marketing and youth access restrictions such as the ones agreed to in 1997 in negotiations between the tobacco companies and the state attorneys general in the United States. Those restrictions include the elimination of all human images (including the Marlboro Man) and substantial reductions in retail signage and displays. Philip Morris agreed to do that in 1997. Why not now? 
- Accept government authority to regulate tobacco and nicotine.

By undertaking these steps, Philip Morris will ensure that youth smoking will decline and eventually adult smoking will as well.

Levy accepts that some people will question Philip Morris's commitment to do the right thing and says that she hopes that reasonable people will judge the company by its actions in the long term. The public health community, of which Campaign for Tobacco-Free Kids is a part, consists of reasonable people. We do judge Philip Morris by its actions. We look at the death toll from tobacco, the high levels of tobacco use by young people, and the tobacco industry's political contributions and influence, and we draw the obvious conclusions.

We hope that things will change as soon as possible. The status quo works against the health of children worldwide.

William D Novelli president

Campaign for Tobacco-Free Kids, Washington, DC, USA

wnovelli@tobaccofreekids.org

\section{Children are another group at risk of hyponatraemia perioperatively}

EDITOR-Our poor understanding and practice of giving fluid and electrolytes perioperatively spans all age groups. The editorial by Lane and Allen highlighted elderly postmenopausal women as being particularly at risk of hyponatraemia postoperatively, ${ }^{1}$ as has been emphasised in several case series, ${ }^{23}$ and the electronic responses to the editorial also concentrated on this age group (www.bmj.com/cgi/ content/full/318/7195/1363\#responses).

The use of hypotonic saline is standard practice for the paediatric age group. This practice is based on calculations of normal physiological requirements for salt and water homoeostasis. These principles were laid down over 40 years ago and have never been challenged, although every year otherwise healthy children suffer brain damage associated with acute perioperative hyponatraemia. ${ }^{4}$ Isotonic solutions are not used in children because it is assumed that their kidneys cannot handle a salt load.

The basic flaw that prevents us understanding the cause of these catastrophes is our assumption that normal physiological rules apply. They don't, and we are frequently undone by the subtleties of secretion of antidiuretic hormone. Practically everything that happens to a patient in the perioperative period is guaranteed to turn on secretion of antidiuretic hormone and inhibit the excretion of electrolyte free water when the situation demands.

Even when an isotonic or near isotonic solution is given surgical patients can become hyponatraemic. In a study by Steele et al 21 out of 22 patients who received only these types of fluid showed a fall in serum sodium concentration from a mean of 140 to $136 \mathrm{mmol} / \mathrm{l}^{5}$ The explanation became evident from the urine sodium measurements, which showed that most patients were excreting a hypertonic urine (sodium concentration $150 \mathrm{mmol} / \mathrm{l}$ ) and were in positive water balance. This implied that antidiuretic hormone was acting, a combination of events referred to by the authors as "desalination."

In a case series of 23 children with acute hyponatraemia presenting with convulsions that I have collected seven of them were excreting a hypertonic urine at presentation despite having a serum sodium concentration of $<125 \mathrm{mmol} / \mathrm{l}$ (data submitted for publication). Much can be learnt from measuring urine sodium concentrations and calculating not only fluid but tonicity balances (sodium plus potassium).

Acute hyponatraemia leading to brain damage is largely preventable but only if we learn to understand that normal physiology is frequently perturbed perioperatively. We need to recognise the prodromal symptoms and be aware that any postoperative patient is potentially at risk. Finally, the use of hypotonic saline should be prohibited perioperatively and reserved only for situations in which the administration of electrolyte free water is genuinely needed.

Desmond Bohn paediatric intensive care specialist Department of Critical Care Medicine, Hospital for Sick Children, 555 University Avenue, Toronto, Ontario M5G 1X8, Canada

dbohn@sickkids.on.ca

1 Lane N, Allen K. Hyponatraemia after orthopaedic surgery. BMJ 1999;318:1363-4. (22 May.)

Ayus JC, Wheeler JM, Arieff AI Postoperative hyponatremic encephalopathy in menstruant women. Ann hyponatremic encephalop

3 Ayus JC, Arieff AI Chronic hyponatremic encephap Ayus J C, Arieff Al. Chronic hyponatremic encephalopath in postmenopausal women: association of therapies wi

4 Arieff AI, Ayus JC, Fraser CL. Hyponatraemia and death or 4 Arieff AI, Ayus JC, Fraser CL. Hyponatraemia and death or
permanent brain damage in healthy children. BMJ

1992;304:1218-22.

5 Steele A, Gowrishankar M, Abrahamson S, Mazer CD, Feldman RD, Halperin ML. Postoperative hyponatremia despite near-isotonic saline infusion: a phenomenon of desalination. Ann Intern Med 1997;126:20-5.

\section{How often should we go to the dentist?}

\section{Editorial gave incorrect source of data}

EDITOR-I congratulate Kay on her succinct appraisal of the issues surrounding the question of the optimum interval between dental check ups. ${ }^{1}$ I fully endorse all her arguments and conclusions, but the editorial contains one specific error, which I wish to draw to readers' attention.

Kay cites a published abstract by my colleague Moles referring to work by our group on the identification of optimal recall intervals for bitewing radiography based on a computer simulation. ${ }^{2}$ She states that the data on rates of progression of dental caries used by Moles in our computer model were derived from a study by her and coworkers. ${ }^{3}$ In fact this is not the case.

All the input data used in our computer simulations of the caries process over time, and sensitivity analyses of treatment outcomes under different sets of conditions, were obtained from original field research by Moles and myself, alone or in collaboration with others. As regards rates of progression of caries, for example, we were interested not only in the progress of existing carious lesions in tooth enamel, quoted by Kay, but also in rates of attack of new caries in clinically sound teeth. This was in order to replicate as closely as possible the conditions in real life.

The data were therefore derived from published research of our own, which also related to the particular age group of interest to us-adolescents and young adults. ${ }^{4}$ The sources of the remaining data, including an assessment of the validity of dentists' treatment decisions which I conducted in association with Kay, are referenced in another of our recent publications ${ }^{5}$ and in a forthcoming article reporting fully our work on optimal intervals for bitewing radiographic examinations.

Martin C Downer emeritus professor Eastman Dental Institute, London WC1X 8LD m.downer@mailbox.ulcc.ac.uk

1 Kay EJ. How often should we go to the dentist? BMJ 1999;319:204-5. (24 July)

2 Moles DR. Assessing interventions: the case for restorative care. Comm Dent Health 1999;16:57

3 Kay EJ, Brickley M, Knill-Jones R. Restoration of approximal carious lesions-application of decision analysis. Comm Dent Oral Epidemiol 1995;23:271-5.

4 Brabner D, Downer MC, Moles DR, Naylor MN. Initial caries attack and average progression rates in 12-year-old Isle of Wight children. Comm Dent Health 1995;12:190-3.

5 Downer MC, Moles DR. Health gain from restorative dental treatment evaluated by computer simulation. Comm Dent Health 1998:15.32-9.

Every other year is probably sufficient for non-smoking adults

EDITOR-Kay's editorial on the use of dental services reminds us of the persistent gradient in oral health favouring those in higher socioeconomic groups. ${ }^{1}$ The author highlights the difficulties in defining an appropriate frequency of dental check ups.

Optimising intervals between routine check ups remains an important issue. ${ }^{2}$ The economic aspect of this should perhaps be evaluated separately for children, adults, and elderly people; dental care for children and elderly people is usually organised within the public health services in several European Union countries, but adults of working age are usually faced with the fee for service dental care market. The cost and perceived value of treatment affect adults' consumption of dental care, especially regular asymptomatic dental visiting.

In a recent report I showed that among male industrial workers access to a dental benefit scheme provided by their employer significantly improved use of dental services, reduced severe periodontitis, and benefited the caries status. ${ }^{3}$ The study and control groups were similar in age, education, and income and also in terms of dental knowledge and attitudes towards dental care and its health implications. Nevertheless, a majority in both groups (94\%) stated that the programme (the lack of it in the control group) had most influence on their current 
dental visiting. The study also showed that the in-house dental care programme helped to stabilise the treatment mix and annual treatment time as well as significantly decrease operative treatment. The regular attenders had a 16 month recall interval on average

Thus it is fair to assume that adults' oral ill health can be reduced by third party payment, especially on the lower socioeconomic levels. Better oral health among populations tends not only to reduce dental emergencies but may also contribute to fewer general health hazards. ${ }^{4}$ Regular dental visiting may also help with the diagnosis and monitoring of stress related craniofacial disorders and reduce the workload of other healthcare staff. ${ }^{5}$ Although the dentist is the only professional to assess the normative oral treatment need of a patient, he or she cannot alone assume responsibility for increasing regular asymptomatic dental check ups; the issue should also be the concern of healthcare administrators.

So how often, then? My study findings do not support biannual routine check ups for every non-smoking adult without specific health problems. Although dental treatment has to be based on individual needs, on the population level a dental check up every other year would perhaps suffice.

Jari Ahlberg chief dental officer

Finnish Broadcasting Company, BOX 80, 00024

YLE, Helsinki, Finland

jari.ahlberg@yle.fi

Kay EJ. How often should we go to the dentist? $B M J$ 1999:319:204-5. (24 July)

2 Sheiham A. Is there a scientific basis for six-monthly dental examinations? Lancet 1977;ii:442-4.

3 Ahlberg J. Implications of a subsidized dental care program for Ahlberg J. Implications of a subsidized dental care program for oral health and its detan 4 Mattila KJ, Nieminen MS, Valtonen VV, Rasi VP health and acute myocardial infarction. BMJ 1989;298 $779-81$.

5 Kuttila M, Kuttila S, LeBell Y, Alanen P. Association between TMD treatment need, sick leaves and use of health care services for adults. J Orofac Pain 1997;11:242-8.

\section{Author's reply}

EDITOR-I beg Downer's pardon for incorrectly citing the sources of data in my editorial. At the conference that I referenced, I had understood from what Moles said that the data used by the team were those referred to in reference 5 in Downer's letter. I apologise for my error.

Ahlberg's letter raises some extremely salient issues-in particular the point that the frequency of dental visiting first came to the attention of academics at least 22 years ago (reference 2 in his letter). I wholeheartedly agree with his contention that the problem should be evaluated separately for different age groups, particularly because the progression of caries is considered to be faster in children and because the sequelae of disease can be of considerably greater impact in children than adults.

Ahlberg emphases the fact that other diseases may be related to oral health and dental care. This is true but brings us back to my key argument-that to confuse optimal recall intervals for individuals with optimum recall intervals for populations will lead to disease (of whatever nature) being left undiagnosed in individuals who need treatment and also to unnecessary repeat examinations in healthy individuals.

Elizabeth J Kay professor of dental health services research

Turner Dental School, University of Manchester, Manchester M15 6FH

\section{Only about 1 in 30 predictions of assault by discharged psychiatric patients will be correct}

EDITor-The debate about the dangerousness of discharged psychiatric patients is interesting. ${ }^{12}$ In public debate (and sometimes also among professionals) it is often claimed that discharged patients are responsible for a substantial number of violent assaults in society. This is sometimes held as a reason for more custodial, institutionalised treatment.

In 1987 Wistedt and I studied the possibility of using a prediction of the likelihood of violence, assessed at discharge from involuntary psychiatric care, as a means of reducing rates of violence in Swedish society. ${ }^{3}$ Our calculations showed that, at most, 100 serious assaults a year in Sweden were committed by patients who had been discharged during the previous year from involuntary psychiatric treatment-that is, less than $1 \%$ of all patients discharged. Trieman et al estimated that $2 \%$ of their population of discharged patients committed serious violent acts within the five years after discharge (that is, $0.4 \%$ a year). ${ }^{2}$

When discussing the possibility of preventing these serious acts of violence the possibility of predicting statistically rare events must be taken into account. ${ }^{4}$ Beck showed in 1985 why the psychiatric profession fails in predicting violence after discharge from an institution. ${ }^{5}$ The reason is not lack of knowledge of risk factors important for future violence but rather a statistical impossibility.

The ability to make a correct prediction depends not only on the accuracy of the classification of future offenders (sensitivity) but also on the correct identification of all future non-offenders (specificity). If we assume that the psychiatric profession succeeded in predicting with $90 \%$ sensitivity and $90 \%$ specificity (a very high accuracy) our Swedish sample showed that for every correct prediction of violence after discharge from an institution, 11 patients would be falsely predicted to commit serious violence. Given the same predictive accuracy and Trieman et al's annual rate of violent patients discharged of $0.4 \%,{ }^{2}$ the ratio of correct to false positive predictions of assault would be about 1 in 30 .

If the consequences for the patients who are positively predicted to be violent include some kind of extended incarceration the question of prediction becomes a moral issue since those interventions made would be not for the benefit of the patient but rather a precaution for society. From an ethical viewpoint, prediction of violence and restraining psychiatric patients into more custodial care is not only useless for society but bears extremely high costs for those many patients falsely predicted to become violent

Tom Palmstierna

Centre for Dependency Disorders, St Göran's Hospital, PO Box 125 60, S-102 29 Stockholm, Sweden

tom.palmstierna@mailbox.euromail.se

1 Geddes J. Suicide and homicide by people with mental illness. BMJ 1999;318:1225-6. (8 May.)

2 Trieman N, Leff J, Glover G. Outcome of long stay psychiatric patients resettled in the community: prospective cohort study. BMJ 1999;319:13-6. (3 July.)

3 Palmstierna T, Wistedt B. Psykiatrin kan inte axla samhällets ansvar för skydd mot våldsbrottslngar [Psychiatry cannot take society's responsibility for protection against violent criminal acts]. Läkartidningen 1987;84: $2768-9$

4 Rosen A. Detection of suicidal patients: an example of some limitations in the prediction of infrequent events. Consult Psychol 1954;18:397-403.

5 Beck JC. Psychiatric assessment of potential violence: a reanalysis of the problem. In: Beck JC, ed. The potentially violent patent act the Taresoff decisi violent patient and the Tarasoff decision in psychiatric practice.

\section{$\mathrm{ABC}$ of labour care}

\section{Obstetric anaesthetists are important in labour care}

EDITOR-We wish to rectify an important omission in the ABC of Labour Care-that is, the role of the obstetric anaesthetist on the labour ward. The report on confidential inquiries into maternal deaths in the United Kingdom in 1994-6 highlights the importance of multidisciplinary care for pregnant women and establishes lack of teamwork as an identifiable cause of substandard care.

The leading causes of maternal death in the United Kingdom are thromboembolism, pregnancy induced hypertension, amniotic fluid embolism, and haemorrhage. Publications from the Royal College of Obstetricians and Gynaecologists emphasise the need for early involvement of anaesthetists in the management of major haemorrhage, ${ }^{2}$ and an anaesthetist has an essential role in managing other life threatening obstetric emergencies. Many sick mothers are now admitted to intensive or high dependency care units. Early involvement of the anaesthetist on the labour ward facilitates earlier transfer of sick mothers; delay in transfer has been identified as a cause of substandard care in mothers who die in childbirth.

The article on operative deliveries refers to the desirability of regional anaesthesia but fails to state the main risks of general anaesthesia-namely, difficult or failed endotracheal intubation, resulting in hypoxia and aspiration of gastric contents. ${ }^{3}$ Early identification of mothers at risk of operative delivery enables regional analgesia to be instituted before urgent caesarean section becomes necessary. Conducting trials of instrumental delivery in the operating theatre with an anaesthetist present 
facilitates immediate extension of regional block for caesarean section.

Many women with coexisting medical disease are now becoming pregnant. Early identification and multidisciplinary antenatal care of these women has been recommended. One of us runs a regular antenatal clinic for women with medical and anaesthetic problems in pregnancy, which operates in parallel with the high risk obstetrician led antenatal clinic. This has improved communication between disciplines in the management of women with coexisting disease.

The latest report on the confidential inquiries recommends the appointment of more consultant anaesthetists with a special interest in pregnancy. It emphasises the importance of communication between all those responsible for the care of women in childbirth. This has been echoed in two editorials, ${ }^{45}$ one of which notes that in some centres $70 \%$ of women in labour may require the services of the obstetric anaesthetist. ${ }^{4}$ We believe that it is essential to involve the anaesthetist in the care of pregnant women.

Dominic Aldington specialist anaesthetic registrar

Diana Brighouse consultant anaesthetist

Shackleton Department of Anaesthesia

Southampton General Hospital, Southampton

SO16 6YD

dbrig@globalnet.co.uk

1 Why mothers die. Report on confidential enquiries into maternal deaths in the UK 1994-1996.London: HMSO, 1998.

2 Royal College of Obstetricians and Gynaecologists. Derizing standards from the maternal mortality reports. London: RCOG, 1994.

3 Chamberlain G, Steer P. ABC of labour care: Operative delivery. BMJ 1999;318:1260-4. (18 May.)

4 Crowhurst JA, Plaat F. Why mothers die-report on confiCrowhurst JA, Plaat $\mathrm{F}$. Why mothers die-report on confi-
dential enquiries into maternal deaths in the United Kingdential enquiries into maternal deaths in

dom 1994-96. Anaesthesia 1999;54:207-9.

5 May AE. The confidential enquiry into maternal deaths 1994-1996. Int J Obstet Anesth 1999;8:77-8.

\section{Authors' reply}

EDITOR-Aldington and Brighouse highlight the crucial role of obstetric anaesthetists on the modern labour ward. One of us (PS) was one of the authors of the article and is writing this reply with the hospital's director of obstetric anaesthesia to emphasise that we do indeed work as a team, as recommended by the authors. We agree that anaesthetists are vital not merely as technicians supplying pain relief on request but also as peripartum physicians supervising the acute management of women in relation to conditions related to pregnancy such as pre-eclampsia. They also play a leading part in coordinating the care of women with major medical disorders such as congenital cardiac disease (in our unit last year we delivered 56 women with (mainly congenital) heart disease, as well as many others with complex medical problems).

At the Chelsea and Westminster Hospital our high risk pregnancy team comprises five specialist obstetricians, two obstetric physicians, six specialist midwives, ${ }^{1}$ a perinatal psychiatrist, and, crucially, five specialist obstetric anaesthetists (and we have a weekly perinatal meeting, which includes the neonatologists). As in many other obstetric units around the United Kingdom, the obstetric anaesthetists have more fixed sessions on the labour ward than the obstetricians. The specialty of obstetric anaesthesia in the United Kingdom has grown so that that there are probably more obstetric anaesthetists involved in labour ward care than practising perinatal obstetricians. This is a tribute to the work of the Obstetric Anaesthetists' Association, of which Brighouse is a leading member and which we strongly support.

At the Chelsea and Westminster Hospital we work closely as a team, and although each woman has a "lead consultant" obstetrician, in practice we all care for one another's patients when we are on duty. Apart from the weekly perinatal meeting, we have a management meeting once a month at which we discuss logistics and policy and ratify guidelines produced by our clinical effectiveness group. Obstetric and anaesthetic guidelines are constantly available on our intranet on over 800 PC terminals throughout the hospital. The obstetric anaesthetists take part in our high risk antenatal clinics each week, where women can see a midwife, obstetrician, obstetric physician, and anaesthetist in a "one stop shop."

We are sorry if the ABC did not highlight these issues, but it was primarily pathophysiology based rather than process based. We are grateful for this opportunity to confirm that we do indeed practise as Aldington and Brighouse preach.

Philip Steer professor of obstetrics

Steve Yentis director of obstetric anaesthesia Chelsea and Westminster Hospital, London SW10 9NH

1 Bradshaw C, Lewis P, Steer PJ. A midwifery team for highrisk pregnancies. Modern Midwife 1995;5:26-9.

\section{Fetus papyraceus is being registered increasingly in Wessex}

EDITOR-Pharoah emphasises the importance of registering a fetus papyraceus for the parenting of the livebirth co-conceptus, counselling for future pregnancies, and research purposes. ${ }^{1}$ At a time when interhospital league tables of mortality are becoming commonplace, however, it is also important to ensure comparability of stillbirth statistics that take fetus papyraceus into account.

The Confidential Enquiry into Stillbirths and Deaths in Infancy (CESDI) provides the means to monitor in detail all deaths from 20 weeks of pregnancy to one year after birth. In Wessex the notification of fetus papyraceus has occurred only recently due to increased liaison with pathologists and the regional fetal medicine unit and scrutiny of all death notifications (and results of postmortem examinations if done) by the inquiry's regional survey office. This practice has resulted in increased ascertainment when compared with the Office for National Statistics (table).

Distortion of stillbirth statistics exists: of the 12 cases reported in Wessex, only five
Numbers of cases of fetus papyraceus notified in Wessex, 1993-8 (excludes terminations and late fetal losses) *

\begin{tabular}{ccc} 
Year & No of cases notified & $\begin{array}{c}\text { Survey ascertainment } \\
\text { as \% (No) }\end{array}$ \\
\hline 1993 & 0 & $89.0(323 / 363)$ \\
\hline 1994 & 0 & $86.7(295 / 340)$ \\
\hline 1995 & 0 & $88.8(409 / 461)$ \\
\hline 1996 & 1 & $96.5(394 / 355)$ \\
\hline 1997 & 7 & $100(394 / 394)$ \\
\hline 1998 & 4 & $100(331 / 331)$ \\
\hline
\end{tabular}

${ }^{*}$ Data not directly comparable with figures published by Office for National Statistics because data here are based on year death was registered, not on year death occurred.

have been registered with the Office for National Statistics as stillbirths-all from one hospital. This situation has occurred because of the rigorous application of section 5 of the Births and Deaths Act of 1926 to a $30 \mathrm{~g}$ stillborn infant by a local registrar that was subsequently enforced by the registrar general in 1996.

The law is clear: the deaths of cotwins must be reported if they are expelled from the mother after 24 weeks of pregnancy, regardless of the gestational age at the time of death. In reality the registration of fetus papyraceus by obstetricians and midwives remains incomplete in most maternity hospitals and consequently distorts the stillbirth statistics. Allowance for such distortion has already been made when hospital death rates in Wessex have been compared, ${ }^{23}$ as suggested by Pharoah, ${ }^{4}$ and used successfully by both the hospital and the health authority concerned.

Pharoah recommends that note should be made of whether parental choice has been exercised when the sex of the fetus is registered. Of the five cases registered with the Office for National Statistics, four were notified to the Confidential Enquiry into Stillbirths and Deaths in Infancy as sex indeterminate and the remaining one was assigned as female yet no postmortem examination or weight was recorded to support this designated sex.

Melanie J Gompels regional CESDI coordinator Wessex Institute for Health Research and Development, University of Southampton, Mailpoint 727, Southampton SO16 7PX M.J.Gompels@soton.ac.uk

David Davies consultant obstetrician and gynaecologist

Portsmouth Hospitals NHS Trust, Portsmouth PO3 6AD

1 Pharoah POD. Anomalies occur in registrations of fetal deaths in multiple pregnancies. BMJ 1999;319:188. (10 July.)

2 Gompels MJ. CESDI Wessex and the Channel Islands. Annual report 1997. Southampton: Wessex Institute for Health Research and Development, University of Southampton, 1998.

3 Gompels MJ. CESDI Wessex and the Channel Islands. Interim report 1998 (in press)

4 Pharoah POD. Registration is important for research into cerebral palsy. BMJ 1997;314:441.

\section{Rapid responses} $e \mathrm{BM}$

Correspondence submitted electronically is available on our website www.bmj.com 